\title{
PW02-015 - Eight years HPFS experience in a single UK centre
}

\author{
DM Rowczenio ${ }^{*}$, H Trojer, G Wang, PN Hawkins, HJ Lachmann, A Baginska, T Russell, R Al-Nackkash, A Bybee \\ From 7th Congress of International Society of Systemic Auto-Inflammatory Diseases (ISSAID) \\ Lausanne, Switerland. 22-26 May 2013
}

\section{Introduction}

In 2004 we established a formal clinical service for patients with hereditary periodic fever syndromes (HPFS). Patients are either referred directly for clinical evaluation, or undergo initial genetic screening on receipt of blood or DNA sample and clinical details via our secure online request procedure: http://www.ucl.ac. $\mathrm{uk} /$ medicine/amyloidosis/nac/genetic_testing

\section{Objectives}

To evaluate eight years experience of a dedicated fever clinic and associated laboratory service at the National Amyloidosis Centre.

\section{Methods}

Between 2004 and 2009 the basic genetic screen encompassed FMF gene $M E F V$ exons 2 and 10; TRAPS gene TNFRSF1A exons 2-6; MKD gene $M V K$ exons 9 and 11 and CAPS gene NLRP3/CIAS1 exon 3. When deemed appropriate, these tests were extended to additional exons on a case by case basis. From 2010 additional genes were added to our repertoire: NOD2 (exons 2 and 4) associated with Crohn's Disease and Blau Syndrome; NLRP12 (exons 2 and 3) associated with familial cold autoinflammatory syndrome 2 and IL36RN (exons 2-5) associated with DITRA.

In each case the specific analyses were determined by the NAC physicians after clinical assessment or on the review of information provided by the external clinician.

\section{Results}

Since January 2005, 3063 patients have undergone genetic screening at the NAC; 996 were assessed directly at the fever clinic (33\%), and blood or DNA were received on a further 2067 (67\%). $M E F V$ was most frequently requested (75\%), followed by TNFRSF1A (58\%), MVK (42\%) and NLRP3 (29\%), other genes accounted for 6\%.

Genetic variants were identified in 1048 patients (34\%): 627 (60\%) had an amino acid variation in $M E F V$ (56\% had a single variant including $34 \%$ who had E148Q, 33\% were compound heterozygotes and 11\% homozygotes). TNFRSF1A variants were found in 133 cases (13\%); $M V K$ in 74 (7\%) (in $58 \%$ we were unable to detect a second variant despite screening of all exons); NLRP3 in 103 (16\%) and NOD2 in 46 (4\%). In 19 patients we identified genetic aberrations in more that one HPFS gene. 28 novel variants were discovered: 9 in NLRP3; 6 in TNFRSF1A; 7 in MVK; 5 in MEFV and 1 in NOD.

\section{Conclusion}

Since creation of the HPFS clinical service in 2004, demand for genetic testing has grown substantially, including a $125 \%$ increase in referrals during the past year. In many cases two or more HPFS genes were screened. We found 1234 genetic variants in 1048 screened cases, of which nearly $40 \%$ accounted for low penetrance sequence variants of undetermined significance including $M E F V$ E148Q, TNFRSF1A R92Q and P46L, MVK S52N and NLRP3 V198M and Q703K. Interestingly we found 19 patients with variations in more than one HPFS gene. In 16 of these we were able to make a clinical diagnosis: 7 had CAPS; 5 MKD; 3 TRAPS and 1 FMF; the remaining 3 had atypical autoinflammatory phenotypes.

An overlap in clinical features between different HPFS highlights the importance of genetic testing in providing accurate diagnosis, leading to appropriate treatment and improvement of quality of life.

Medicine, University College London, London, UK 


\section{Disclosure of interest}

None declared.

Published: 8 November 2013

doi:10.1186/1546-0096-11-S1-A155

Cite this article as: Rowczenio et al:: PW02-015 - Eight years HPFS

experience in a single UK centre. Pediatric Rheumatology 2013 11(Suppl

1):A155.

Submit your next manuscript to BioMed Central and take full advantage of:

- Convenient online submission

- Thorough peer review

- No space constraints or color figure charges

- Immediate publication on acceptance

- Inclusion in PubMed, CAS, Scopus and Google Scholar

- Research which is freely available for redistribution 